\title{
To assess the efficacy of reproductive health and family planning multimedia educational package for tribal Women
}

\author{
SUMAN VERMA, RENU DHAKAR AND AZAD MORDIA
}

Received: 21.11.2016; Revised: 27.03.2017; Accepted: 13.04.2017

See end of the paper for authors' affiliations SUMAN VERMA

Department of Human Development and Family Studies, College of Home

Science, Maharana Pratap University of Agriculture and Technology, UDAIPUR (RAJASTHAN) INDIA
ABSTRACT : Objectives: To assess the efficacy of the educational package on reproductive health and Family planning for tribal women, Methods/Statistical Analysis: The study used experimental research design specifically pre -post equivalent group design to assess the level of knowledge before and after exposure of educational package. Present study consist 60 tribal women (30 each in experimental and controlled group) age of 18 -35 yrs. from Balicha village, Girwa tahsil from Udaipur district of Rajasthan. Structured interview schedule (Pre test - post test) was administered. The pretest was conducted and the educational package was administered. The post test was conducted after five days. The collected data were analyzed by using percentage and paired $t$ test. Findings: Experimental group increase their level of knowledge after exposure to the intervention package and controlled group who were not expose to intervention was not increase their knowledge and post testing result revealed the significant difference between experimental and controlled group at 1 per cent level of significance which shows the effectiveness of education package. Study revealed that appropriate and meaningful content, utilization of multiple interesting methods and aids along with good presentation enhance post test knowledge among experimental group regarding Reproductive Health and Family Planning.

KEY WORDS: Reproductive health, Family planning, Tribal women, Multimedia educational package

- HOW TO CITE THIS PAPER : Verma, Suman, Dhakar, Renu and Mordia, Azad (2017). To assess the efficacy of reproductive health and family planning multimedia educational package for tribal women. Asian J. Home Sci., 12 (1) : 77-80, DOI: 10.15740/HAS/AJHS/12.1/77-80. 